\title{
Acute effects of alcohol on the peripheral nerves in diabetic polyneuropathy: a clinical and neurophysiological study
}

\author{
JUHANI JUNTUNEN, ${ }^{*}$ TAPANI SALMI, $\dagger$ KIMMO SAINIO, $\ddagger$ REINO YLIKAHRI,§ ESKO \\ MATIKAINEN*
}

\begin{abstract}
From the Neuroscience Group, Institute of Occupational Health, Helsinki, ${ }^{*}$ the Laboratory of Clinical Neurophysiology, Department of Neurology, $\dagger$ the Laboratory of Clinical Neurophysiology, Department of Pediatrics, $¥$ University of Helsinki, and the Research Laboratories of the State Alcohol Monopoly, $§$ Helsinki, Finland
\end{abstract}

SUMMARY Acute effects of alcohol on the peripheral nerves of seven patients with diabetic polyneuropathy and 13 healthy subjects were examined neurophysiologically. Ethanol $(1 \mathrm{~g} / \mathrm{kg})$ caused a slight increase in skin temperature and motor conduction velocity in both groups. Motor distal latencies decreased in the healthy subjects, but increased among polyneuropathic patients after the consumption of alcohol. Diabetic nerves appear most susceptible to the acute effects of alcohol.

The deleterious effect of the chronic consumption of alcohol on the peripheral nerves of human alcoholics has been established. ${ }^{2}$ Research into the chronic effects of the consumption of alcohol in animals recently has provided new data on the basic neuropathologic phenomena which occur in the peripheral nerves during the development of alcoholic polyneuropathy..$^{3-5}$ The acute effect of alcohol intoxication on the function of the peripheral nerves has been studied previously both in normal healthy humans ${ }^{67}$ and in animals. ${ }^{8-11}$ However, there are no data on the acute effects of alcohol on damaged nerves. The effect of moderate alcohol intoxication on the function of peripheral nerves both in normal healthy controls and in patients with diabetic neuropathy was the purpose of the present study.

\section{Patients and methods}

Thirteen healthy volunteers (eleven men and two women) and seven patients with diabetic polyneuropathy (six men and one woman) were examined. The mean age of the polyneuropathic patients was 39.8 years (range 30-59

Address for reprint requests: Dr J Juntunen, Neuroscience Group, Institute of Occupational Health, Haartmaninkatu 1, SF-00290, Helsinki 29, Finland.

Received 20 September 1981 and in revised form 10 December 1981. Accepted 19 December 1981 years); the mean age of the controls was 29.2 years (range $22-41$ years). The patients had had diabetes for a mean duration of $17 \cdot 1$ years (range 2-30 years). Six of the patients had juvenile diabetes and one had adult diabetes, and they were all dependent on insulin, all were normotensive and in good metabolic control at the time of the examinations. None showed any signs of cardiovascular or renal complications. Their peripheral vascular state generally was good, with the exception of one patient (RL) who had varicose ulcerations in the lower extremities. None of the healthy controls showed signs of peripheral neuropathy, but each diabetic patient had clinical signs of polyneuropathy, which was confirmed by neurophysiological measurements. For statistical purposes the neurological findings were scored using a numerical index. A value of 0 was assigned if the finding was normal, 1 if it was diminished or altered, and 2 if it was absent. The reflexes of the biceps, the patella and the ankle were scored, as were sensitivity to light touch, sensitivity to pain, and sensitivity to vibration. This evaluation scale, which had a potential range of 0 to 12 points has been used in other clinical studies of diabetic polyneuropathy. ${ }^{12}$ The duration of the sense of vibration was carried out with a standard tuning fork (128C); the measurements were taken from the medial malleoli of the feet and from the metacarpophalangeal eminences of the hands. Detailed data of the clinical characteristics of each patient are shown in table 1; the differences between the diabetics and the controls with regard to the sensitivity to vibration are provided in table 2.

Nerve conduction velocities were measured using a 3-channel DISA electromyograph. Table 2 shows which nerves were measured for nerve conduction velocity. Sur- 
Table 1 Age and sex of the diabetic patients with polyneuropathy, durations of their diabetes, and the clinical score for the severity of polyneuropathy

\begin{tabular}{|c|c|c|c|c|}
\hline Patient & $\begin{array}{l}\text { Age } \\
\text { (yr) }\end{array}$ & Sex & $\begin{array}{l}\text { Duration of diabetes } \\
(y r)\end{array}$ & Score \\
\hline $\begin{array}{ll}\text { 1. } & \text { RS } \\
\text { 2. } & \text { PK } \\
\text { 3. } & \text { EA } \\
\text { 4. } & \text { JV } \\
\text { 5. } & \text { LL } \\
\text { 6. } & \text { HH } \\
\text { 7. } & \text { RL }\end{array}$ & $\begin{array}{l}59 \\
37 \\
30 \\
31 \\
31 \\
46 \\
45\end{array}$ & $\begin{array}{l}\text { male } \\
\text { male } \\
\text { male } \\
\text { male } \\
\text { female } \\
\text { male } \\
\text { male }\end{array}$ & $\begin{array}{r}8 \\
29 \\
16 \\
2 \\
25 \\
10 \\
30\end{array}$ & $\begin{array}{l}6 \\
4 \\
5 \\
6 \\
5 \\
2 \\
8\end{array}$ \\
\hline
\end{tabular}

Table 2 Conduction velocities for the sensory (SCV) and motor $(M C V)$ nerves $(\mathrm{m} / \mathrm{s})$ in the control group and in diabetics before the consumption of ethanol

\begin{tabular}{lll}
\hline Nerve & Controls & Diabetics \\
\hline Median, MCV & $62 \cdot 8$ & $51 \cdot 0$ \\
Ulnar, MCV & $58 \cdot 7$ & $49 \cdot 6$ \\
Peroneal prof. MCV & 49.7 & $32 \cdot 6$ \\
Radial, SCV & $56 \cdot 1$ & $52 \cdot 8$ \\
Sural, SCV & 42.6 & 38.9 \\
Vibration time (s) & & \\
Medial malleoli & & \\
(n=6) & & \\
Hands & 14.5 & 9.2 \\
(n=7) & 27.0 & $17 \cdot 3$ \\
\hline
\end{tabular}

face electrodes were used both for stimulation and recording. The positions of the electrodes were marked in order that exactly the same sites could be used in all the measurements. The stimulus pulses were supramaximal rectangular with a duration of $0.1 \mathrm{~ms}$. Before the measurements, the appropriate extremity was warmed by an infrared heater. Skin temperatures were monitored at wrist level and, in most cases, was kept constant. On some occasions, for technical reasons, a sufficient heating time was not possible and some increase in temperature after alcohol took place. The motor conduction velocities (MCV) of one or both median, ulnar and deep peroneal nerves were measured. Also measured were the sensory conduction velocities (SCV) of the radial and sural nerves. As the muscle and nerve action potentials in the lower extremities of the neuropathic patients were very low, their measurements were inaccurate; therefore, they were omitted from the statistical analysis. The nerve conduction velocities before the consumption of alcohol are shown in table 2 .

The subjects drank ethyl alcohol $(1.0 \mathrm{~g} / \mathrm{kg})$ diluted with orange juice to a concentration of about $20 \%(\mathrm{v} / \mathrm{v})$. They had 20 minutes to drink the alcohol. The concentration of ethyl alcohol in the blood one hour after the subjects began the consumption of alcohol was $0.82 \pm 0.07 \mathrm{mg} / \mathrm{ml}$ among the diabetics and $0.95 \pm 0.05 \mathrm{mg} / \mathrm{ml}$ among the controls. The concentrations of ethanol in the blood were measured with a Perkin Elmer gas cromatograph. ${ }^{13}$ The first neurophysiological measurements were taken just before the ingestion of alcohol, and the second measurements were taken one hour later. Before the experiment, each diabetic patient had the usual breakfast and medication. One of them showed signs of slight hypoglycaemia when the second neurophysiological measurements were taken.

\section{Results}

The mean skin temperature of both the controls and the diabetics was $33 \cdot 2^{\circ} \mathrm{C}$ before and after the consumption of alcohol. The slight increase in temperature after the consumption of ethanol was in the control group $0.50^{\circ} \mathrm{C}$, and in the diabetics $0.20^{\circ} \mathrm{C}$; the difference between the groups was not significant (fig 1).
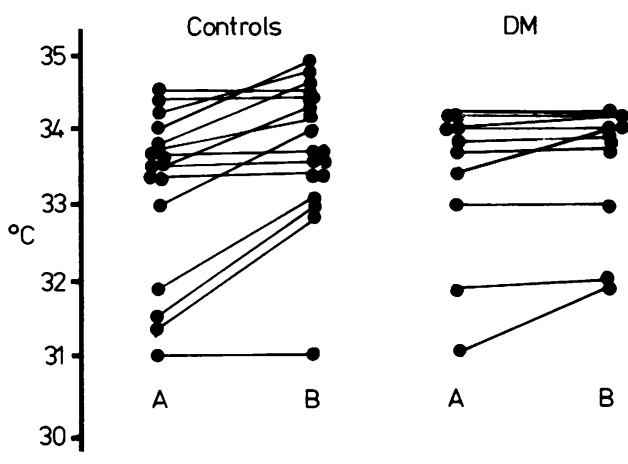

Fig 1 Skin temperatures before $(A)$ and after $(B)$ the consumption of ethanol. Mean skin temperature at wrist level was $33.2^{\circ} \mathrm{C}(S D \pm 1.4)$ in both groups. The mean temperature increase $\left(0.50^{\circ} \mathrm{C}\right.$ in controls, $0.20^{\circ} \mathrm{C}$ in diabetics) did not differ between the groups.

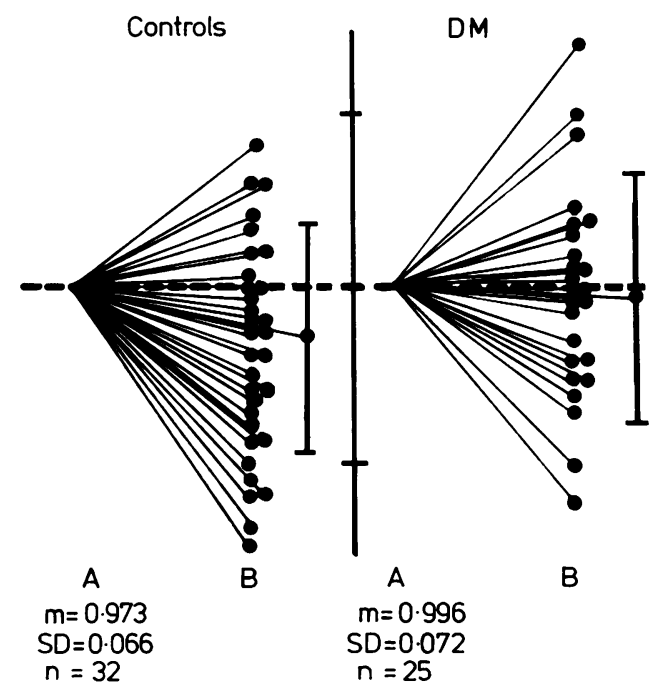

Fig 2 Relative changes in the motor conduction velocities (MCV) of the median and the ulnar nerves, presented as $1 / M C V(M C V \pm S D)$ before $(A)$ and after $(B)$ the consumption of ethyl alcohol. The difference between the normal controls and the patients with diabetic neuropathy (DM) was not significant $(0.040>p>0.020)$. 
In agreement with the increase in skin temperatures, there was a slight increase in the MCVs of both groups. The differences between the groups were not statistically significant (fig 2 ). Distal sensory conduction velocities in the radial nerve of the healthy subjects tended to increase, while no change occurred in the polyneuropathic patients (fig 3). Motor distal latencies, which are summarised in fig 4 , decreased among the controls. Although individual variation between the diabetic patients was great, the distal latencies increased after the consumption of alcohol. The difference of the responses between the controls and the diabetic patients was significant $(p<0.01)$.

\section{Discussion}

The present experiment revealed an interesting and unexpected difference between the healthy subjects and the diabetic neuropathic patients with regard to the response of the distal parts of the peripheral nervous system to acute alcohol intoxication. Before our results are interpreted, several aspects should be taken into consideration. Under normal conditions, the conduction velocity of the myelinated fibres depends on the ratio of axonal diameter to total fibre diameter, on the distance between active nodal regions, that is, internodal length, on the ambient temperature,,$^{14}$ and, of course, on the supply of metabolic products necessary for the maintenance of axonal function. Because measurements of the conduction velocities of the peripheral nerves involve the summation of the CVs of a myriad of individual nerve fibres, a reduction in the CVs of neuropathic patients could be due partly to the disappearance of

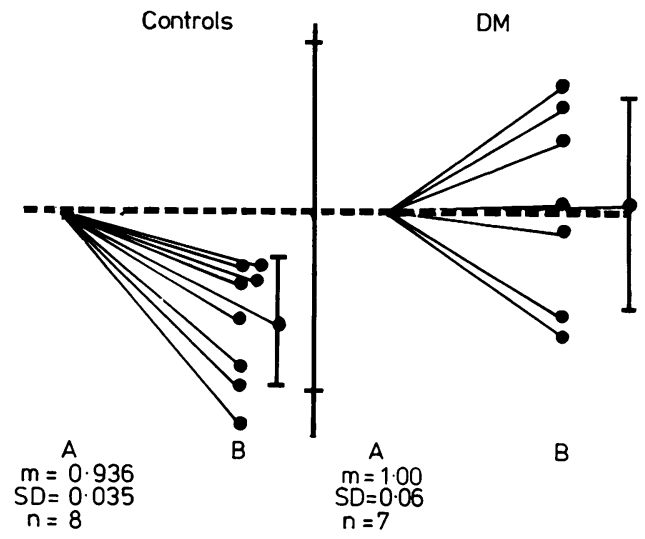

Fig 3 Relative changes in the sensory conduction velocities (SCV) of the radial nerve, expressed as $1 / S C V(M \pm S D)$ before $(A)$ and after $(B)$ the consumption of ethanol.

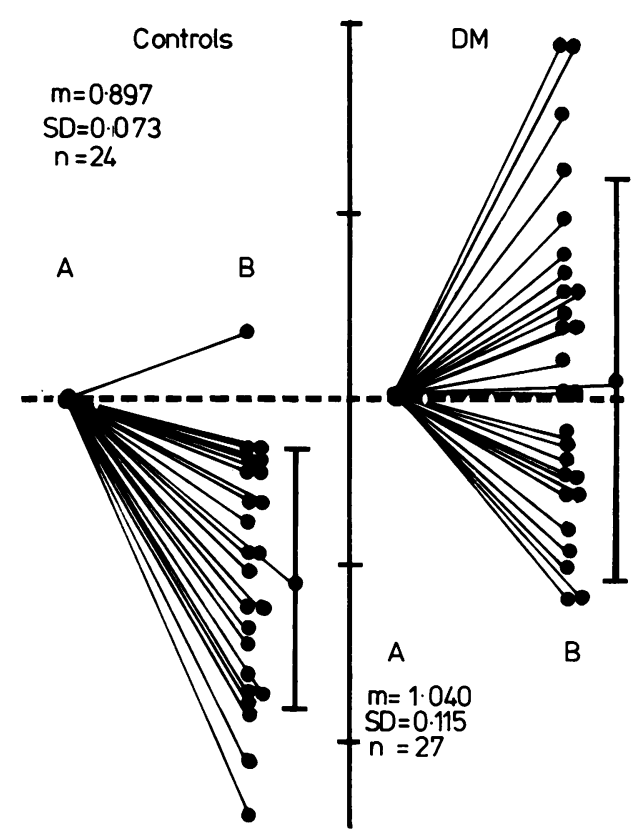

Fig 4 Motor distal latencies of the median and ulnar nerves $(M \pm S D)$ before $(A)$ and after $(B)$ the consumption of ethanol. The difference of the responses between the controls and the neuropathic subjects (DM) was significant $(p<0.01)$.

larger axons which conduct more rapidly. Morphometric analyses of nerve biopsies have shown that both diabetic polyneuropathy, and many other neuropathies cause loss of larger axons. ${ }^{15}$

Another particularly important factor in this study was the temperature. The rates at which sodium and potassium channels undergo transition from a low conductance state to a high one depends upon temperature, probably reflecting the effects of enzymatic turnover-rates in the nerve membranes. ${ }^{1617}$ Alcohol causes cutaneous vasodilatation which leads to a rise in the temperature of the skin and associated structures. Such a rise in temperature occurred in our patients and controls, but was less in the diabetics probably because of vasomotor disturbances due to autonomic neuropathy. ${ }^{18}$ This change in temperature should have affected the neurophysiological responses of both controls and diabetics in the same manner but the response of the neuropathic nerves with regard to sensory conduction velocities and, in particular, distal latencies differed from that of controls. The distal latencies in the controls decreased after the consumption of alcohol, probably due to an effect of temperature rise combined with the possible effect of ethanol on the nerve, but that of the diabetics increased. 
Another factor to consider was the concentration of glucose in the blood at the time of the measurements. The most common pathologic feature of patients with diabetic neuropathy is a reduction of motor and sensory conduction velocities. ${ }^{19}$ Motor and sensory conduction velocities are related to the concentration of glucose in the blood. As the level of glucose in the blood falls, for example as occurs when treatment for diabetes is begun, conduction velocity improve $;{ }^{20}$ distal latencies behave in a similar manner. The present experiment, however, did not entail extensive alterations in the level of glucose in the blood; moreover, the entirely different responses between the groups cannot be explained by fluctuations in the blood glucose level.

Our results on the acute effects of alcohol on distal latencies of the healthy controls are comparable with those obtained previously. About $100 \mathrm{mg} / 100$ $\mathrm{ml}$ of blood ethanol concentration causes a reduction in distal latencies, ${ }^{6}$ probably owing to alcoholinduced temperature changes in the limb. ${ }^{7}$ How, then, can the opposite response in diabetic neuropathic patients be explained? Distal motor latency is the interval of time required for the nerve impulse to travel along the distal parts of the motor nerve-a distance of 5-7 cm-and through the synaptic cleft, after which the impulse initiates the muscle action potential. Alcohol has both presynaptic and postsynaptic effects ${ }^{8}$ and animal experiments have shown that neuromuscular transmission is facilitated even after low doses of ethanol. ${ }^{11}$ Despite these results, however, most of the response due to ethanol are caused by altered nerve conduction. Diabetic polyneuropathy is a mixed sensori-motor neuropathy, with both axonal nerve damage (dying-back) and segmental demyelination. As in many mainly metabolic neuropathies which have lasted for a prolonged period, continuous degeneration and regeneration occurs in the peripheral nerves. Consequently, the metabolism of the Schwann cells and the neurons is different from that which occurs under normal conditions. It is possible that, owing to their prevailing degeneration and regeneration, neuropathic nerves react in an entirely different way to acute ethanol intoxication. The basic neurophysiological events underlying the different reaction of damaged nerves to alcohol remain to be discovered.

Another interesting question arising from this study is whether the abnormal response to alcohol is specific to diabetic neuropathy. Some data suggest that this response also may be different in patients with alcoholic polyneuropathy (Juntunen et al unpublished). Furthermore, both clinical experience and a carefully examined case ${ }^{21}$ indicate that the consumption of alcohol may have some beneficial effect on the subjective symptoms experienced by patients with polyneuropathy. This may partly account for the high prevalence of excessive consumption of alcohol among patients with diabetic neuropathy. ${ }^{22}$

This work was supported by the Finnish Foundation for Alcohol Studies (Dr J Juntunen).

\section{References}

${ }^{1}$ Victor M. Polyneuropathy due to nutritional deficiency and alcoholism. In: Dyck PJ, Thomas PK, Lambert EH, eds. Peripheral neuropathy. Vol. 2. London: WB Saunders 1975:1030-66.

${ }^{2}$ Bechse F, Bucthal F. Alcoholic neuropathy: clinical, electrophysiological and biopsy findings. Ann Neurol 1977;2:95-110.

${ }^{3}$ Juntunen J, Teräväinen H, Eriksson K, Panula P, Larsen A. Experimental alcoholic neuropathy in the rat: histological and electrophysiological study on the myoneural junctions and the peripheral nerves. Acta neuropath (Berl) 1978;41:131-7.

4 Juntunen J, Teräväinen H, Eriksson K, Larsen A, Hillbom M. Peripheral neuropathy and myopathy. An experimental study of rats on alcohol and variable dietary thiamine. Virchows Arch (Pathol Anat) 1979;383:241-52.

5 Bosch EP, Pelham RW, Rasool CG, et al. Animal models on alcoholic neuropathy: morphologic, electrophysiologic and biochemical findings. Muscle Nerve, 1979;2:133-44.

${ }^{6}$ Low MD, Basmajian JV, Lyons GM. Conduction velocity and residual latency in the human ulnar nerve and the effects of ethyl alcohol. Am J Med Sci 1962;244:92-102.

${ }^{7}$ Peiris OA, Miles DW, Anderson WN. The action of ethyl alcohol on the peripheral nerves. Am J Med Sci 1966;251:207-10.

${ }^{8}$ Gage PW. The effect of methyl, ethyl and n-propyl alcohol on neuromuscular transmission in the rat. $J$ Pharmacol Exp Ther 1965;150:236-43.

9 Wallgren H, Barry H. The actions of alcohol. Vol 1. Amsterdam: Elsevier 1970.

${ }^{10}$ Reed TE. Effect in vivo of a sub-hypnotic dose of ethanol on nerve conduction velocity in mice. Life Sci 1979;25:1507-11.

$"$ Reed TE. Acute effects of ethanol in vivo on neuromuscular transmission. Pharmacol Biochem Behavior 1980;13:811-15.

12 Matikainen E, Leinonen H, Juntunen J. Capillary circulation and muscle blood flow in diabetic neuropathy. Europ Neurol. 1981 (in press).

${ }^{13}$ Eriksson CJP, Sippel HW, Forsander OA. The determination of acetaldehyde in biological samples by headspace gas chromatography. Anal Biochem 1977;80:116-24.

14 Barchi RL. Excitation and conduction in nerve. In: Sumner AJ, ed. The Physiology of Peripheral Nerve Disease. Philadelphia: WB Saunders 1980:1-40. 
${ }^{15}$ Ochoa J. Criteria for the assessment of polyneuropathy. In: Spencer PS, Schaumburg HH, eds. Experimental and Clinical Neurotoxicology. Baltimore: Williams \& Wilkins 1980:681-707.

${ }^{16}$ Hodkin AL, Huxley AF. Currents carried by sodium and potassium ions through the membrane of the gian axon of Loligo. J Physiol (Lond) 1952;116:449-72.

17 Moore JW, Joyner RW, Brill MH, Waxman SD, NajarJoa M. Stimulations of conduction in uniform myelinated fibers. Biophys J 1978;21:147-60.

${ }^{18}$ Clarce BF, Ewing DJ, Campbell, IW. Diabetic autonomic neuropathy. Diabetologia 1979;17:195-212.
${ }^{19}$ Thomas P. Human and experimental diabetic neuropathy. In: Canal N, Pozza G, eds. Peripheral Neuropathies. Elsevier: 1978:239-55.

${ }^{20}$ Gregersen G. Variations in motor conduction velocity produced by acute changes of the metabolic state in diabetic patients. Diabetologia 1968;4:273-7.

${ }^{21}$ Juntunen J, Sainio K. Effects of alcohol upon symptoms of polyneuropathy. Lancet 1976:254.

${ }^{22}$ McCulloch DK, Campbell IW, Prescott RJ, Clarke BF. Effects of alcohol intake on symptomatic peripheral neuropathy in diabetic men. Diabetes Care $1980 ; 3 ; 2: 245-7$. 